\title{
Mössbauer Spectroscopy Study of Laboratory Produced ODS Steels
}

\author{
J. Degmová*, J. Dekan, J. Šimeg Veterníková and V. Slugeñ \\ Institute of Nuclear and Physical Engineering, Faculty of Electrical Engineering and Information Technology, \\ Ilkovičova 3, 81219 Bratislava, Slovakia
}

\begin{abstract}
The investigated oxide dispersion strengthened steels were received from laboratories involved in the Coordinated Research Project F11014 "Benchmarking of Structural Materials Pre-selected for Advanced Nuclear Reactors", namely from India (IGCAR), Russia (Bochvar Institute), China (University of Beijing), and Japan (Kyoto University). The application of the Mössbauer spectroscopy on these materials is aimed to reveal the complex information about studied materials via unique characteristics as micromagnetic properties and homogeneity of admixtures distribution in steels. All studied steels mainly differ in content of elements as $\mathrm{Cr}$ or $\mathrm{Al}$. Chosen fitting model consists of bcc Fe, bcc Fe with $\mathrm{Cr}$ substitution and paramagnetic bcc Cr rich components. These ODS steels are aimed in further study for He implantations.
\end{abstract}

DOI: 10.12693/APhysPolA.131.1171

PACS/topics: 29.30.-h, 76.80.+y, 81.05.-t, 81.05.Bx, 82.80.Ej

\section{Introduction}

Several recently developed structural materials have very promising characteristics, especially for application in primary components of innovative nuclear reactors. Among them the special attention should be given to oxide dispersion strengthened (ODS) steels developed for the application in cooling systems, reactor vessel or fuel cladding since they act as the main barriers to release fission products [1]. The continued activities related to their research, development and qualification are needed and should combine studies of their long-term stability and microstructural behavior. However, despite many broad R\&D programs and earlier industrial production of ODS-alloys, this alloy class cannot be introduced on an industrial level at present. Remaining open issues such as an optimized alloy composition and production as well as partially low fracture toughness and anisotropic material properties (especially for ferritic ODS alloys) requires further R\&D investments and a strong international cooperation of scientific and industrial institutions. One of the challenges for ODS steels is that they must combine excellent high temperature mechanical property, good corrosion resistance and excellent neutron irradiation resistance. While some composition designs on one hand increase the corrosion resistance, may on the other hand deteriorate the high temperature mechanical property or irradiation resistance. The influence of composition adjustment on the microstructure and performance of the ODS steels is thus one of the main issues [2-4].

In the present work the microstructural properties of different laboratory produced ODS steels were investigated via application of the Mössbauer spectroscopy.

*corresponding author; e-mail: jarmila.degmova@stuba.sk
The investigated ODS steels were received from laboratories involved in the IAEA Coordinated Research Project F11014 "Benchmarking of Structural Materials Pre-selected for Advanced Nuclear Reactors". The most significant advantage of the Mössbauer spectroscopy, with regard to the investigation of steels, is its high sensitivity to changes in atomic configuration of resonant atoms $\left({ }^{57} \mathrm{Fe}\right)$ in the immediate neighborhood of substitution atoms. This technique, via the hyperfine interactions, provides information on the magnetic state, electrical interaction, chemical bonding, local crystal symmetry, lattice defects, dynamic parameters, elastic stress, etc. $[5,6]$. The application of the Mössbauer spectroscopy on laboratory produced materials is aimed to reveal the complex information about studied materials via unique characteristics as micromagnetic properties and homogeneity of admixtures distribution in steels.

\section{Experimental details}

The investigated ODS steels were received from laboratories involved in the CRP - ODS project - India (IGCAR), Russia (Bochvar Institute), Japan (Kyoto University) and China (University of Beijing) [7]. They were prepared by standard powder metallurgy route of fabrication which consists of gas atomization of a pre-alloy, mechanical alloying, consolidation and thermal/mechanical treatment. The details on chemical composition are showed in Table I. The produced steels were either in the shapes of discs or tubes. The samples for the Mössbauer experiments were prepared by careful scrapping of original material into powder form. The identification of the samples was done as follow: $9 \mathrm{Cr}$ - IGCAR, EP $450-$ Bochvar Institute, KOT - Kyoto University, $16 \mathrm{Cr}-$ University of Beijing.

Spectra were recorded in transmission geometry at room temperature using constant-acceleration Wissel Mössbauer spectrometer with the ${ }^{57} \mathrm{Co}(\mathrm{Rh})$ source. The isomer shifts were determined relative to natural iron. 
Hyperfine parameters of the spectra including spectral area $\left(A_{r e l}\right)$, isomer shift (IS), as well as mean hyperfine magnetic field $\left(B_{h f}\right)$ were refined using the CONFIT fitting software [8]. The accuracy in their determination is of $\pm 1 \%$ for relative area, $\pm 0.04 \mathrm{~mm} / \mathrm{s}$ for isomer shift and $\pm 1 \mathrm{~T}$ for hyperfine field, respectively. Relative areas of spectral components determine relative quantification of phase composition.

According to [9], the chosen fitting procedure depends on the amount of $\mathrm{Cr}$ in $\mathrm{Fe}-\mathrm{Cr}$ alloys. In the case of 9 to $13.6 \mathrm{wt} \% \mathrm{Cr}$ containing samples the applied fitting model consists of four components. The spectra of broadened lines are decomposed into three magnetically split components, the hyperfine field of one of which slightly differs from that of pure $\mathrm{Fe}(34 \mathrm{~T})$ and the values of two others, which are lower, $31 \mathrm{~T}$ and $29 \mathrm{~T}$, respectively. The first sextet ( $34 \mathrm{~T})$ has to be assigned to Fe-atoms in the iron matrix that are mostly surrounded by Fe atoms in their first coordination shells (named as Fe), while the two other magnetically split subspectra $\left(B_{h f 1} \approx 31 \mathrm{~T}\right.$, $\left.B_{h f 2} \approx 29 \mathrm{~T}\right)$ have to be associated with iron atoms surrounded in their first or second coordination shells by alloying elements (named as $\mathrm{Fe}-\mathrm{Cr}$ ). Similar fitting model was used by Petrov et al. [9]. Minor paramagnetic singlet in the middle of the spectrum can be described as chromium rich bcc $\alpha^{\prime}$ phase [10]. Despite its contribution into the spectra is very small (in the range of error), the asymmetry in the middle of the spectra is clearly visible and thus this component needs to be included into fitting model. With increasing $\mathrm{Cr}$ content the amount of components decrease to two magnetically splitted $\left(B_{h f 1} \approx 27-28 \mathrm{~T}, B_{h f 2} \approx 22-23 \mathrm{~T}\right)$ subspectra. In the case of $16 \mathrm{wt} \% \mathrm{Cr}$ the magnetic phase contribution in the spectrum is still clearly visible [7].

TABLE I

Detailed composition of studied ODS steels.

\begin{tabular}{c|c}
\hline \hline ID & Composition \\
\hline 9 Cr & $0.1 \mathrm{C} 9 \mathrm{Cr} 2 \mathrm{~W} 0.2 \mathrm{Ti0} .35 \mathrm{Y} 2 \mathrm{O} 3$ \\
EP 450 & $0.01 \mathrm{C} 1 \mathrm{Si} \mathrm{Mn} 13 \mathrm{Cr} 0.3 \mathrm{~V} 0.33 \mathrm{Y} 2 \mathrm{O} 30.015 \mathrm{~B} 3.7 \mathrm{Mo}$ \\
KOT 19 & $0.04 \mathrm{C} 13.6 \mathrm{Cr} 1.9 \mathrm{~W} 0.02 \mathrm{Al} 0.16 \mathrm{Ti0} 0.33 \mathrm{Y} 2 \mathrm{O} 3$ \\
KOT 17 & $0.03 \mathrm{C} 14.7 \mathrm{Cr} 1.9 \mathrm{~W} 3.3 \mathrm{Al} 0.51 \mathrm{Zr} 0.33 \mathrm{Y} 2 \mathrm{O} 3$ \\
KOT 18 & $0.03 \mathrm{C} 14.73 \mathrm{Cr} 1.9 \mathrm{~W} 3.8 \mathrm{Al} 0.46 \mathrm{Hf} 0.32 \mathrm{Y} 2 \mathrm{O} 3$ \\
$16 \mathrm{Cr}$ & $0.08 \mathrm{C} 0.75 \mathrm{Si} 2 \mathrm{Mn} 16 \mathrm{Cr} 0.1 \mathrm{~N} 0.35 \mathrm{Y} 2 \mathrm{O} 2 \mathrm{Mo}$
\end{tabular}

\section{Results and discussion}

The obtained Mössbauer spectra differ according to $\mathrm{Cr}$ content i.e. as the $\mathrm{Cr}$ content increases, the Mössbauer spectra become more complex, transforming from ferritic structure to austenitic-martensitic one. They are shown in Fig. 1 and their corresponding Mössbauer parameters are listed in Table II. With gradually increased $\mathrm{Cr}$ content the $\mathrm{Fe}-\mathrm{Cr}$ phases form almost whole area of the spectrum. The Mössbauer spectrum of the $9 \mathrm{Cr}$ steel containing 9 wt\% of $\mathrm{Cr}$ is shown in Fig. 1a. The sextet with $B_{h f}$ close to $34 \mathrm{~T}$ contributes quite significantly to the spectrum, while to the chromium rich $\alpha^{\prime}$ phase is attributed only $1 \%$ of the spectrum, which is the value within the frame of experimental error. The Mössbauer spectrum of sample named as EP 450 is shown in Fig. 1b. This spectrum of $13 \mathrm{wt} \% \mathrm{Cr}$ steel exhibits lower amount of non-pure bcc Fe phase in comparison with the spectrum of $9 \mathrm{Cr}$ steel (decrease to $5 \%$ ). On the contrary, the amount of $\mathrm{Fe}-\mathrm{Cr}$ phases reached up to $94 \%$. Amount of chromium rich $\alpha^{\prime}$ phase remained unchanged (1\%). The Mössbauer spectra of ODS steels containing 13.6$14.73 \mathrm{wt} \%$ of $\mathrm{Cr}$, namely samples KOT 19 , KOT 17 , and KOT 18 are shown in Fig. 1c-e.

\section{TABLE I}

Data obtained from fitting procedure. Resulting hyperfine parameters include spectral area $\left(A_{\text {rel }}\right)$, mean hyperfine magnetic field $\left(B_{h f}\right)$ and isomer shift (IS).

\begin{tabular}{c|c|c|c|c}
\hline \hline ID & Component & $A_{r e l}[\%]$ & $B_{h f}[\mathrm{~T}]$ & IS $[\mathrm{mm} / \mathrm{s}]$ \\
\hline 9 Cr & Fe, Fe-Cr, & 19,20, & $34.1,31.2$, & $-0.02,-0.04$, \\
& Fe-Cr, $\alpha^{\prime}$ & 60,1 & 29.2 & $-0.04,0.02$ \\
EP 450 & Fe, Fe-Cr, & 5,21, & $34.2,31.1$, & $0.00,-0.02$, \\
& Fe-Cr, $\alpha^{\prime}$ & 73,1 & 27.4 & $0.00,-0.02$, \\
KOT 19 & Fe, Fe-Cr, & 4,18, & $34.0,30.7$, & $0.00,0.00$, \\
& Fe-Cr, $\alpha^{\prime}$ & 77,1 & 27.3 & $-0.03,0.02$ \\
KOT 17 & Fe-Cr, Fe-Cr & 56,44 & $27.9,23.5$ & $-0.01,-0.05$ \\
KOT 18 & Fe-Cr, Fe-Cr & 55,45 & $27.0,22.7$ & $0.02,-0.04$ \\
16 Cr & martensite, & 53, & 24.7 & -0.03, \\
& austenite & 47 & 24.7 & -0.12
\end{tabular}

The Fe rich phase and chromium rich $\alpha^{\prime}$ phase were detected only in the case of KOT 19 sample. The Mössbauer spectra of sample KOT 17 and KOT 18 do not show sextets of narrow lines which can be seen in all previously mentioned samples, identified as non-pure bcc Fe phase. The spectra can be decomposed into two components [9], with mean hyperfine field values $B_{h f 1} \approx 27 \mathrm{~T}$, $B_{h f 2} \approx 22 \mathrm{~T}$, respectively. These two sextets of hyperfine field distribution can be assigned to phases of bcc iron with gradually increasing $\mathrm{Cr}$ content in the samples. In both cases, the whole spectrum is composed of the $\mathrm{Fe}-\mathrm{Cr}$ mixture, no pure bcc Fe or bcc $\mathrm{Cr}$ content phases were observed in those samples.

The reason for absence of the iron rich phase and chromium rich $\alpha^{\prime}$ phase in the case of KOT 18 and KOT 17 samples could be due to elevated amount of $\mathrm{Cr}$ content which is in the case of both samples around $14.7 \mathrm{wt} \%[11,12]$, despite of the fact that those two materials are containing $\mathrm{Al}$ which is known as alloying elements encouraging of $\alpha$-Fe formation [13]. The paramagnetic singlet significantly contributes to the spectrum of ODS steel containing $16 \mathrm{wt} \%$ of $\mathrm{Cr}$ (see Fig. 1f). It represents austenitic fcc Fe phase. Magnetic part of the spectrum can be ascribed as martensite with mean hyperfine field of $25 \mathrm{~T}$. Based on the fitting procedure results, the austenitic phase forms $47 \%$ and martensite $53 \%$ of the spectrum. 

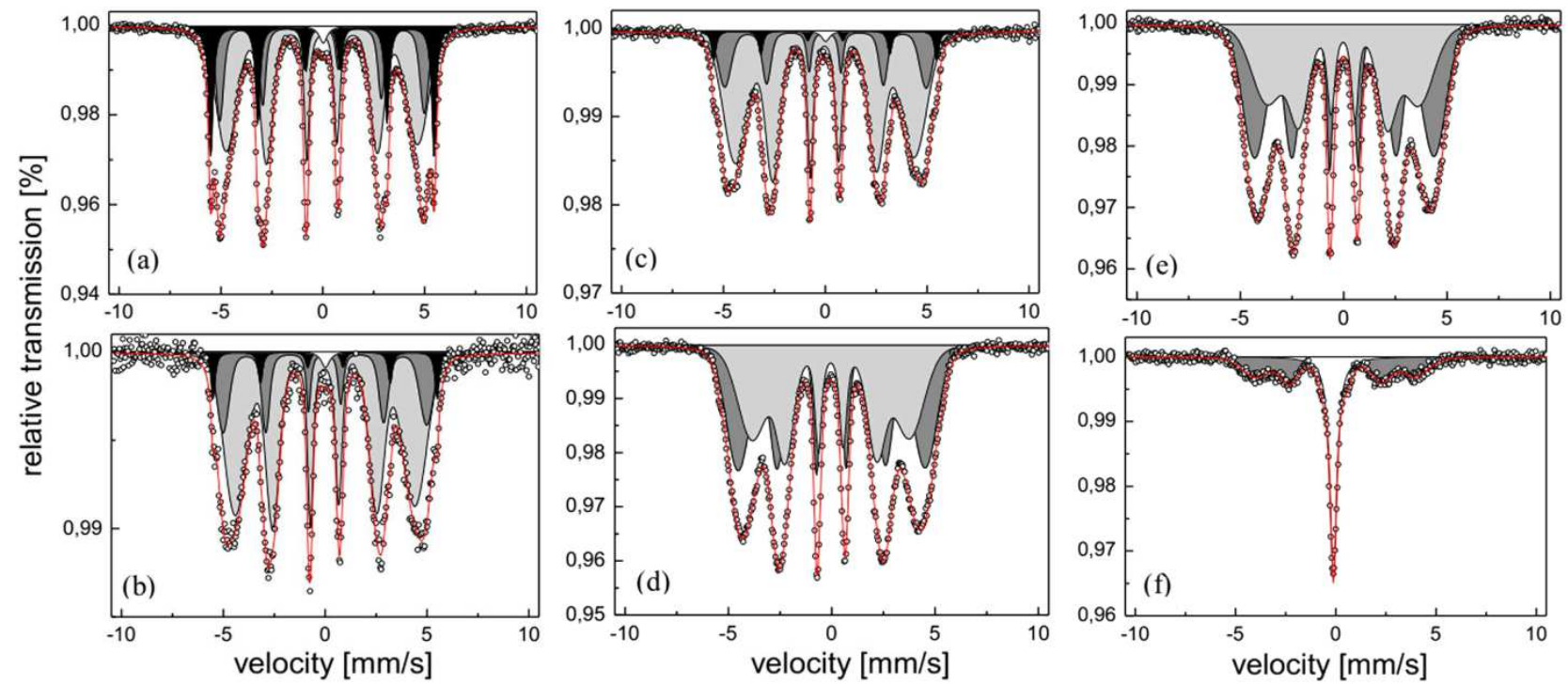

Fig. 1. Mössbauer spectra of $9 \mathrm{Cr}$ (a), EP 450 (b), KOT 19 (c), KOT 17 (d), KOT 18 (e), and 16 Cr (f) of studied ODS steels. Black component ( $\mathrm{a}, \mathrm{b}, \mathrm{c})$ represents non-pure bcc Fe phase, dark and light grey components (a-e) represent bcc Fe with $\mathrm{Cr}$ substitutions in the lattice ( $\mathrm{Fe}-\mathrm{Cr}$ phase). White component represents bcc $\mathrm{Cr}$ rich phase with few Fe substitutions. In the case of $16 \mathrm{Cr}$ sample (f) white component represents austenitic phase and grey component represents martensitic phase.

\section{Conclusions}

In the presented work the laboratory produced ODS steels with Cr content ranging from 9 to $16 \mathrm{wt} \%$ were investigated by the Mössbauer spectroscopy, with the aim to reveal the complex information about laboratory produced materials via micromagnetic properties and homogeneity of admixtures distribution in steels. The obtained results showed that even small differences in the $\mathrm{Cr}$ content in the boundary region of phase transition can significantly influence the sample phase composition as well as its micromagnetic properties.

\section{Acknowledgments}

This work was supported by the project VEGA 1/0477/16 and VEGA 1/0204/2013.

\section{References}

[1] M. Inoue, T. Kaito, S. Ohtsuka, NATO Science for Peace and Security Series B: Physics and Biophysics, 2008, p. 311.

[2] Z. Oksiuta, N.L. Baluc, Adv. Mater. Res. 59, 308 (2009).

[3] R. Gao, T. Zhang, X.P. Wang, Q.F. Fang, C.S. Liu, J. Nucl. Mater. 444, 462 (2014).
[4] S. Noh, B.-K. Choi, S.H. Kang, T.K. Kim, Nucl. Eng. Techn. 46, 857 (2014).

[5] L. Cohen, Application of Mössbauer Spectroscopy, Vol. II, Academic Press, New York 1980.

[6] G. Brauer, W. Matz, C. Fetzer, Hyperfine Interact. 56, 1563 (1990).

[7] Coordinated Research Project F11014 Benchmarking of Structural Materials Pre-selected for Advanced $\mathrm{Nu}$ clear Reactors, IAEA 2015.

[8] T. Žák, Y. Jirásková, Surf. Interf. Anal. 38, 710 (2006).

[9] Yu.I. Petrov, E.A. Shafranovska, Yu.F. Krupyanskii, S.V. Essine, J. Appl. Phys. 91, 1 (2002).

[10] L. Malerba, A. Caro, J. Wallenius, J. Nucl. Mater. 382, 710 (2006).

[11] A. Kuronen, S. Granroth, M.H. Heinonen, R.E. Perälä, T. Kilpi, P. Laukkanen, J. Lång, J. Dahl, M.P.J. Punkkinen, K. Kokko, M. Ropo, B. Johansson, L. Vitos, Phys. Rev. B 92, 214113 (2015).

[12] R. Idczak, R. Konieczny, J. Chojcan, J. Phys. Chem. Solids 72, 1095 (2012).

[13] Y. Palizdar, Ph.D. Thesis, The University of Leeds, Leeds 2011. 